\title{
The definition of harm reduction
}

Simon Lenton; Eric Single

Drug and Alcohol Review; Jun 1998; 17, 2; Academic Research Library pg. 213

Drig and Alcobol Revicw (1998) 17, 213-220

\section{HARM REDUCTION DIGEST 1}

Welome to the Harm Retuction Digest, where in each regular edition of Drug and Alcohol Review invited c-authors will contribute to pieces on the theory and practice of barm reduction. While the focus of subsequent HR Digests will be acounts of the pratice of barm reduction interventions, programmes and policies from around the word, it was decided that the forst Digest ought to address the definition of Harm Reduction. Consequently the style of this digest is probubly more fomal than most that will follow it. Many of you will hate read DAR's special issue on barm redution (1995, 14(3)) where Alex Wodak. Bill Saunders, Patricia Erickson, Eric Single and Nick Heatber all addressed the issue of definition in their respective contributions. Since this there bave been a bandful of papers and reports which bove also grappled with the issue of defintion. Co-author of this piece is Professor Eric Single, from the Department of Public Health Siences at the University of Toronto. Eric addressed issues aroi nd the definition of barm reduction in the 1996 Dorotby Black lecture in London and. with Prafessor Timothy Rohl, as independent evaluators of Australia's National Drag Strategy, wroti on the topic in their report Mapping the Future'.

SIMON LENTON

\section{The definition of harm reduction}

\section{SIMON LENTON ${ }^{1} \&$ ERIC SINGLE ${ }^{2}$}

\author{
${ }^{1}$ National Centre for Research into the Prevention of Drug Abuse, Curtin \\ University of Technology, Perth, Australia $\sigma^{2}$ Public Health Sciences, \\ University of Toronto, Canada
}

\section{Introduction}

We aim here to critique some of the previous attempts at definition of harm reduction and to offer what will hopefully be a practical set of criteria for determining whether a given policy or programme should be considered to be harm reduction or not.

We will argue first that the central defining characteristic of harm reduction is that it focuses on reduction of harm as its primary goal rather than reduction of use per se, secondly that strategies are included to reduce the harm for those who continue to use drugs, and thirdly that strategies are included which aim to demonstrate that, on the balance of probabilities, it is likely to result in a net reduction in drug-related harm. We also offer a set of principles, which while not comprising defining criteria, are common to many policies, programmes or interventions which are generally regarded as harm reduction.

Simor Lenton, M Psych (Clin), B Psych, Research Fellow, National Centre for Rescarch into the Prevention of Drug Abuse, Curtin Lniversity of Terhnologr, GPO Box U1987, Perth, Western Australia 6001; « simon@ncrpda.curtin.eduatu >. Professor Eric Single, Professor of Public Healtis Sciences, University of Toronto and Research Associate, Canadian Centre on Substance Abuse, 6 Mervyn Avenue, Toronto. Canada M9B 1M6; <esingleßutoronto a > Correspondence to Mr Lenton. 


\section{Definitions}

In reviewing these definitions we ought remind ourselves as Erickson [1] does "that our interpretations of the term tend to change over time and this is a healthy process that is essential in the full articulation of an 'emerging public health perspective' (p. 283).

\section{Narrow definitions}

Single \& Rohl [2] have noted that the term harm reduction originally referred to only those policies and programmes which attempted to reduce the risk of harm among people who continued to use drugs. Thus the term did not include abstinent-orientated programmes (p. 43). Indeed, Single offered his preferred definition of harm reduction as "a policy or programme directed towards decreasing adverse health, social and economic consequences of drug use while the user continues to use drugs" (p. 12) [3]

Narrow definitions have the advantage of being conceptually clear in that they distinguish harm reduction from other policies and programmes. However, narrow definitions also have some disadvantages. First they deliberately exclude abstinenceorientated treatment and supply reduction strategies which might be constructively included under a harm reduction umbrella (e.g. abstinenceorientated detoxification programmes, cautions for first offenders, custody diversion and court diversion schemes). Secondly, they may be less appropriate for nicotine where, while there are some strategies to reduce harm for tobacco smokers (e.g. low tar cigarettes and incorporating use of nicotine impregnated gum to reduce cigarette consumption), most tobacco strategies are aimed at cessation rather than reduced use.

The first two of these disadvantages seem to us to be the most significant, and they are related. Clearly, most harm reduction approaches would acknowledge that, on a hierarchy of risk one of the possible ways to reduce the harm associated with use of a given drug is to not use at all. It is acknowledged that this may not consider harm in its broadest sense. For example, there may be costs associated with the use of alternative drugs, or the costs of the intervention itself [4]. Howcver, abstinence may be, but is not necessarily, a strategy which can result in a reduction in overall harm. It would therefore seem that to restrict the term to only those policies and programmes which attempted to reduce the risk of harm among people who continued to use drugs is to exclude what may be an effective harm reduction strategy. Furthermore, from a clinical perspective, a finite period of abstinence may be negotiated with a client who is working toward a longer-term goal of controlled or attenuated use. From a policy perspective, the other main disadvantage of a narrow definition of harm reduction is that it does not foster communication between different sections of the drug service provision and intervention area which have been divided across the dimensions of abstinent vs. non-abstinent and supply reduction vs. law reform. This is the major reason why national drug strategies in Australia and Canada, although nominally based on harm reduction, have adopted a broad, all-cncompassing definition of the term.

Some, such as Wodak \& Saunders, have offered possible responses to the criticisms of the narrow definitions of harm reduction. They suggest differentiating reduction of barm which they describe as "any measure which decreases the negative consequences of drug use" from barm reduction, which they reserve for "those specific measures which prevent the baleful consequences of drug use without setting out to achieve this by interfering with drug consumption" (p. 169) [5]. Similarly a national policy group in Canada have suggested differentiating between harm reduction as a broad policy goal, which would include abstinence-based policies and programmes, and harm reduction as a strategy, which is limited to measures aimed at continuing users [6].

While harm reduction measures do not have ceasing use or even necessarily reducing drug use as their primary goal, some harm reduction measures involve using drugs in different (safer) ways or in lower dosages. Examples include needle exchange and the use of non-injecting routes of administration (NIROA). Some of the major drug-related harms such as dependence or overdose can be prevented effectively by strategies which aim to affect or reduce the amount or frequency of drugs. For example, controlled drinking, or "using half first"-in the case of many injectables. There is also evidence that some of the most prevalent and effective naturally occurring harm reduction strategies employed within peer groups of people who use drugs include strategies which impact on the amount or manner of drug use. For example, Gamble \& George in their study of "successful" rec- 
reational drug use describe "positive peer pressure" where drug-using group members feel they have a duty, which appears to be reciprocal, to alert each other to their excessive or inappropriate drug use [7].

\section{Broad definitions}

Broad definitions are those which include any programme and policy aimed at reducing drug-related harm. Wodak \& Saunders note that "to some harm reduction means the employment of any means to reduce the harm resulting from illicit drugs" (p. 269) [5].

The main advantage of broad definitions is that they include abstinent-orientated approaches. For example, since 1985 Australia has had harm minimization as its national policy approach to drugs incorporating supply control, demand reduction and problem prevention. This has provided a common ground which has facilitated members of different sides of the drug treatment and policy debate working together, to a greater or lesser cxtent, to reduce drug-related harm.

The danger, of course, is that a definition will be so broad and over-inclusive that it will include any drug policy and programme as all can claim to reduce drug-related harm in some fashion, and as such will cease to be useful. As Single notes, the problem with this definition is not what it includes but what it fails to exclude, as virtually any policy or programme can be directed towards decreasing health, social and economic adverse consequences [8]. Even 12-Step programmes could be seen as harm reduction, as they could reduce drug-related harm by promoting abstention. Further, Wodak \& Saunders argue that the logical extension of broad definitions would include the creation of drug-free states or the indefinitc incarceration of drug users to prevent them doing harm to themselves or others [5].

\section{Hard empirical definitions}

Hard empirical definitions of harm reduction presume that it is possible to calculate the net gain or loss for a given policy or programme such that those which display a net gain are said to be harm-reducing. For example, Lenton \& Midford in their definition required that a reduction in harm be "directly demonstrated ... rather than claiming or inferring that harm has been reduced from changes in other indices" (p. 412) [9].

The advantages of hard empirical definitions is that they are flexible in that they encompass any programme which can be shown to actually reduce net harm, while at the same time are scientifically appealing as they imply that the decision as to whether a policy or programme is a harm reduction one or not comes down to a simple analysis of data rather than dogma.

There are a number of problems with hard empirical definitions of harm reduction. First, in practice it is almost always impossible to definitively quantify net gain or loss, and when possible it may be exceedingly time consuming and expensive. Secondly, such calculations of harm often only consider only net gain without considering the costs of the intervention, nor the salience of the costs and benefits of drug use or the alternatives from the perspective of the drug users themselves. Thirdly, Single \& Rohl have noted that hard cmpirical definitions do not always correspond to common understandings of the meaning of harm reduction [2].

Hawks \& Lenton note that if one takes the view that the weighing up of costs and benefits can only be done by a simple calculus of harms and benefits then it is hard to imagine how in practice such an equation could ever be "solved" [4]. This is particu. larly the case when deciding which policies ought to be followed at a societal lcvel rather than negotiating harm reduction goals for an individual. There are few examples in public policy where all the possible costs and benefits of any course of action are identified, measured and summed in such a way. In fact, it scems that many policy decisions of farreaching consequence are made with little reference to what "evidence" or data exists.

We will argue below that the measurement, in broad terms, of various costs and benefits of different courses of action will be an important part of deciding on whether a policy, programme or intervention is effective in reducing harm. However, it is not feasible, timcly, or possible to expect that this could be done in such a way as to enable a calculus of harms and benefits to solve the cost benefit equation definitively. In practise decisions have to be made and resources allocated following a less than perfect weighing-up of costs and benefits of different courses of action. The early response to the HIV epidemic in countries such as Australia and 
the United Kingdom are good examples of harms reduced by quick action based on less than perfect evidence.

\section{Preferred definition}

A socio-empirical definition

The definition we offer herc has three necessary conditions. We regard a policy, programme or intervention as being one of harm reduction if, and only if: (1) the primary goal is the reduction of drug related harm rather than drug use per se; (2) where abstinence-orientated strategies are included, strategies are also included to reduce the harm for those who continue to use drugs; and (3) strategies are included which aim to demonstrate that, on the balance of probabilities, it is likcly to result in a net reduction in drug-related harm.

This definition attempts to acknowledge that in practise decisions about whether a policy, programme or intervention is one of harm reduction are made in a dynamic social context where empiricism or measurement has an important role, but does not provide an absolute certainty to the definition. Here we are mindful of Mugford's point that:

Harm reduction is lodged firmly in the postenlightenment discourses that see policy as a matter for rational discussion between reasonable men. (The gender attribution is not a careless slip.) There is a strong sense that harm reduction debates remain untouched by the ferment in modern philosophy and social theory that centres on post-modernism and feminism in particular. Harm reductionists often write and think within the discourse of what Toumlin (1990) calls "high modernity", a position that is characterised by certainty, systemacity and the idea of a "clean slate" [10].

The primary gral is the reduction of drug-related harm rather than drug use per se

First, it is a necessary condition that the primary goal of a policy, programme or intervention is the reduction of drug-related harm rather than drug usc per se. This element is common to many of the previous definitions of harm reduction $[2,9,11,12]$. Use reduction may be a strategy to achieve harm reduction, but when use reduction becomes a goal in its own right the policy or programme should not be described as harm reduction [9]. This is well articulated by Heather, who notes that "the distinction between use reduction and harm reduction programmes appears to be in terms of their primary [or overall/main] goals: the primary goal of use reduction programmes is to reduce use, whereas the primary goal of harm reduction strategies is to reduce harm without necessarily, and depending on particular circumstances, seeking to reduce use" (p. 333) [11]. As Caulkins \& Reuter put it, "the overall goal (of drug policy) ought to be to minimize the harm associated with the production, distribution, consumption and control of illicit substances. Reducing use should be seen as a principal means of attaining that end. However ... it is neither the only way nor a foolproof way" (p. 1149) [13]. Harm reduction is not in conflict with abstincnce as a possible strategy for reducing drug-related harm, even in the long term, but it gives priority to the more immediate and practical goal of reducing harm for users who cannot be expected to stop using at the present time.

A test of this principle would be to ask of policies, programmes or interventions what is their goal and why? If the answer is that the goal is to reduce drug use because drug use is bad, or it is necessarily better to not use drugs, then one would not classify the policy or programme as one of harm reduction. If the answer is that it is to reduce harm, and that use reduction is one of a number of strategies to reduce harm, then one would not exclude the programme or policy as not being harm reduction but would go on to consider the other criteria below.

Strategies are included to reduce the harm for those who continu' to use drugs

Secondly, the policy, programme or intervention must include strategies to reduce the harm for those who continue to usc. Thus, programmes which encourage abstinence as a strategy towards the overall goal of reducing harm would be considered harm reduction if they also have policies, procedures and programmes which also aim to reduce the harm for those who continue to use.

A practical test of this principle would be to ask what strategies are in place to attempt to reduce the harms of those that continue to use drugs? Thus a 
residential detoxification programme which aims for abstinent outcomes but exercises some degree of tolerance (such as cautions and relapse prevention counselling) with lapses to drug use, possession of drugs or paraphernalia; and for example provides "split kits" (packs containing harm reduction information and/or equipment), clean needles for drug injectors who are self or compulsorily discharged, might be seen as a harm reduction in orientation. However, another detoxification programme which summarily discharges people found to be using drugs or in possession of drugs or equipment, with no attempt to reduce harms from use once discharged, would not be considered a harm reduction programme.

Strategies are employed which aim to demonstrate whether the strategy is likely to result in a net reduction in drug-related barm

Thirdly, that strategies are employed which aim to demonstrate whether harm is reduced, or is likely to be reduced. Given that harm reduction programmes aim to reduce harm, a defining characteristic ought to be some attempt to demonstrate that harm has indeed been reduced, or is likely to be reduced. However, whether harm has been reduced or not cannot be a defining characteristic of harm reduction prostammes otherwise all harm reduction programmes must, by definition, be effective. A definition of the term must allow that some harm reduction programmes will be less than effective. Ilere we have adopted the recommendation of Wodak \& Saunders to differentiate "harm reducrion" from "reduction of harm" [5].

Thus an effective harm reduction policy, programme or intervention or is one which can be demonstrated, to a reasonable and informed audience, by direct measurement or otherwise, that that on the balance of probabilities has, or is likely to result in, a net reduction in drug-related harm. This acknowledges, as discussed above, that in practise it is often not possible to definitively measure all costs and benefits of the various courses of action. In reality a demonstration of likely impacts on harms may, for a time in the life of a project be based on research on similar projects elsewhere, while cfforts are made to evaluate the impact of the project of interest by a process of measurement. Additionally, as Strang notes, risk - the possibility that an cvent might occur-might be chosen as as a surrogate measure of harm where it is a more useful "handle" on the possible harm which might be incurred or where harm may not be directly or easily measurable. Yet measurement of harm ought to be the target [12].

When measurement is undertaken this should, where possible, take into account the unintended consequences (both costs and benefits) of the intervention for the community, including those who use the drugs in question, in comparison to available alternatives. However, as Heather notes, the level of measurement needs be no more than a simple ordinal scalc (minor/modcrate/major, or even presence/ absence). What Heather considers essential "is that judgements of degree of harm be made by reasonable, objective, replicable and, as far as possible, consensually agreed rules" (p. 333) [11].

Reduction of harm is often harder to measure than abstention. Newcombe suggests that evaluation first requires the selection of a subset of desired harm reduction goals from a matrix of potential options [14]. His framework, which can guide the measurement of harm reduction outcomes, offers nine categories of drug-related harm from the dimensions of: type (health, social, economic); and level (individual, community, socicty). Thesc occur within a time dimension (short-, medium- and long-term-effects), a duration dimension (temporary, permanent) and a severity dimension (mild, moderate, major). He also notes that harm reduction goals are hierarchical and assessments need to be made as to the propensity of each for achieving the optimum net reduction in overall harm. In our view harm should be interpreted in its broadest sense and include, for example, the impact on the use of other drugs, and the social and economic costs of the intervention. There is no point achieving circumscribed benefits if the cost is substantially exacerbating problems in other domains [14].

At times one will need to argue and infer from what can he measured to what cannot, yet the key issue is that what will be shown to reduce harm will be made in dynamic and subjective social context where rescarch will at best provide some of the major building blocks of measurement. However, judgements of effectiveness will more often than not be made on the basis of incomplete evidence.

The definition would allow that a policy or comprehensive drug strategy (such as that which exists in Australia) which includes a range of strategies might itself be legitimately be called one of harm reduction 
in that it meets the three necessary conditions, yet some of the programmes which operate within it may themselves not meet the criteria (e.g. a treatment service with an exclusively abstinence goal which does nothing to reduce the harms for those who continue to use drugs.

\section{Adrantages of the socio-empirical defnition}

We believe that the advantages of the definition are that, first, it is not so narrow to be limited to only those programmes policies, programmes or interventions which reduce the harm for those who continue to use drugs. Sccondly, it is not so broad as to allow any policy which reduces harm to be termed harm reduction. Thirdly, it has much in common with other definitions of harm reduction in that it $\mathrm{cm}$ phasizes the overall goal of reducing drug-related harm rather than use per se. Fourthly, it provides a common ground where divergent approaches to drug-related harm can be included but only if they meet the above three criteria. In doing this it may provide a case for encouraging programmes which mav have not been seen as harm reduction, adopting strategies which aim to reduce the adverse consequences of drug use for those who continue to use drugs. Furthermore, it provides a rationale for programme evaluation or at least adoption of strategies based on consensually agreed available evidence. Finally, we believe that it is practical and that it does not appear to misclassify policies, programmes and interventions as harm reduction which have generally not been regarded as such.

\section{Disadrantages of the socio-empirical definition}

We believe that the main disadvantage of the definition we offer here is that it may not be possible to apply it to a policy, programme or intervention without a dynamic interaction which may take some time. However, this is a reflection of the way that the world is, and it will be possible for descriptions of policies, programmes or interventions to stipulate how they meet the necessary conditions of the definition.

\section{Harm reduction principles}

While not being defining characteristics of harm reduction the following principles, based on Single
\& Rohl, are shared by many policies, programmes or interventions which are generally considered to be harm reduction [8].

Typically, harm reduction policies, programmes and interventions:

- Avoid exacerbating the harm caused by the misuse of drugs

Avoid exacerbating the harm caused by the misuse of drugs, by consideration of the impacts on indicators of harm including the unintended harms which may result from the strategy itself. For example, does the enforcement of the criminal law against non-dependent infrequent users of a drug, primarily as a deterrent, outweigh the negative impacts such as the costs of enforcement, the impact of a criminal record, and the marginalization of large numbers of citizens?

- Treat drug users with dignity and as normal human beings

Drug users should be treated with dignity and as normal people and they are seen as responsible for their own behaviour.

- Maximize the intervention options

Policics and programmes which aim to reduce harm rather than drug use per se often have the added advantage of opening up for consideration a wider number and variety of intervention options.

- Prioritizing of achievable goals

Harm reduction programmes almost always involve prioritizing of goals, in which immediate and realizable goals take priority when dealing with users who cannot realistically be expected to cease their drug use in the near future, although they do not conflict with adoption of abstention as a way of reducing drug-rclated harm.

- Neutral regarding legalization or decriminalization

Harm reduction should not be equated with the legalization of drugs, and is neutral regarding policy questions such as legalization or decriminalization.

- Very distinct from the 'War on Drugs' approach Harm reduction does and should imply a different strategic direction from that of national strategies such as the US War on Drugs. It implics a concern with reducing the adverse 
consequences of drug use for the society which includes those members of society who happen to use drugs. A war on drugs is in fact a war on drug users-people are jailed, not the drugs they use.

As a reminder that these principles do not define harm reduction, Strang notes that:

The true champion of harm reduction is not necessarily anti drugs; nor necessarily prodrugs. He or she expresses support, opposition or indiffercnce to a proposed public or personal health approach or a proposed legal or social response solely on the basis of the extent to which it increases or decreases the amount of harm consequent upon the drug in question. A pre-determined position on drug use as intrinsically "bad" or "good" has no meaning in this context, where the response is determined solely by the extent of observed or anticipated harm which results from the drug use. Thus the champion of harm reduction is neither for nor against increased civil rights for drug users; neither for nor against the increased availability of drug substitution programmes or drug free programmes; neither for nor against the legalisation or decriminalisation of drug use; neither for nor against diversions from the criminal justice system-except insofar as one or other of these choices influences the nature and extent of harms consequent upon use. (pp. 3-4) [12].

\section{Conclusion}

In conclusion we offer our preferred definition:

A policy, programme or intervention should be called harm reduction if, and only if: (1) the primary goal is the reduction of drug-related harm rather than drug use per se; (2) where abstinence-orientated strategies are included, strategics are also included to reduce the harm for those who continue to use drugs; and (3) strategies are included which aim to demonstrate that, on the balance of probabilities, it is likely to result in a net reduction in drug-related harm.

\section{Acknowledgements}

Thanks to Alex Wodak for his comments on an earlier draft of this paper.

\section{References}

[1] Erickson PG. Harm reduction: what it is and what it is not. Drug Alcohol Rev 1995;14:283-5.

[2] Single E, Rohl T. The National Drug Strategy: mapping the future, Report commissioned by the Ministerial Council on Drug Strategy, Canberra: AGPS, 1997.

[3] Single E. The concept of harm reduction and its application to alcohol: the 6th Dorothy Black lecture. Drugs Prev Policy 1997;4:7-22.

[4] Hawks D, Lenton S. Harm minimisation-a basis for decision making in drug policy? Risk Decision Policy (in press).

[5] Wodak A, Saunders B. Special Issue on harm reduction. Drug Alcohol Rev 1995;14.

[6] CCSA National Working Group on Addictions Policy. Harm reduction. Ottawa: Canadian Centre on Substance Abuse, 1996.

[7] Gamble L, George M. "Really useful knowledge": the boundaries, customs and folk laws governing recreational drug use in a sample of young people. In: Erickson PG, Riley DA, Cheung YT, O'Hare PA, eds. Harm reduction: a new direction for drug policies and programs. Toronto: University of Toronto Press, 1997:340-62.

[8] Single E. Defining harm reduction. Drug Alcohol Rev 1995;14:287-90.

[9] Lenton S, Midford R. Clarifying 'harm reduction'? Drug Alcohol Rev 1996;14:411-13.

[10] Mugford, S. Harm reduction: does it lead where its proponents imagine? In: Heather N, Wodak Nadelmann EA, O'Hare P. eds. Psychoactive drugs and harm reduction: from faith to science. London: Whurr, 1993:21-33.

[11] Heather N. Groundwork for a research programme on harm reduction in alcohol and drug treatment. Drug Alcohol Rev 1995;14:331-6.

[12] Strang J. Drug use and harm reduction: responding to the challenge. In: Heather $N$, Wodak A Nadelmann EA, O'Hare P. eds. Psychoactive drugs and harm reduction: from faith to science. London: Whurr, 1993:3-20.

[13] Caulkins JP, Reuter P. Setting goals for drug policy: harm reduction or use reduction?, Addiction, 1997;92:1143-50.

[14] Newcombe R. The reduction of drug-related harm. A conceptual framework for theory, practice and research. In: O'Hare PA, Newcombe $R$, Mathews $A$, Bunning EC, Drucker E. eds. The reduction of drug related harm. London: Routledge, 1992. 